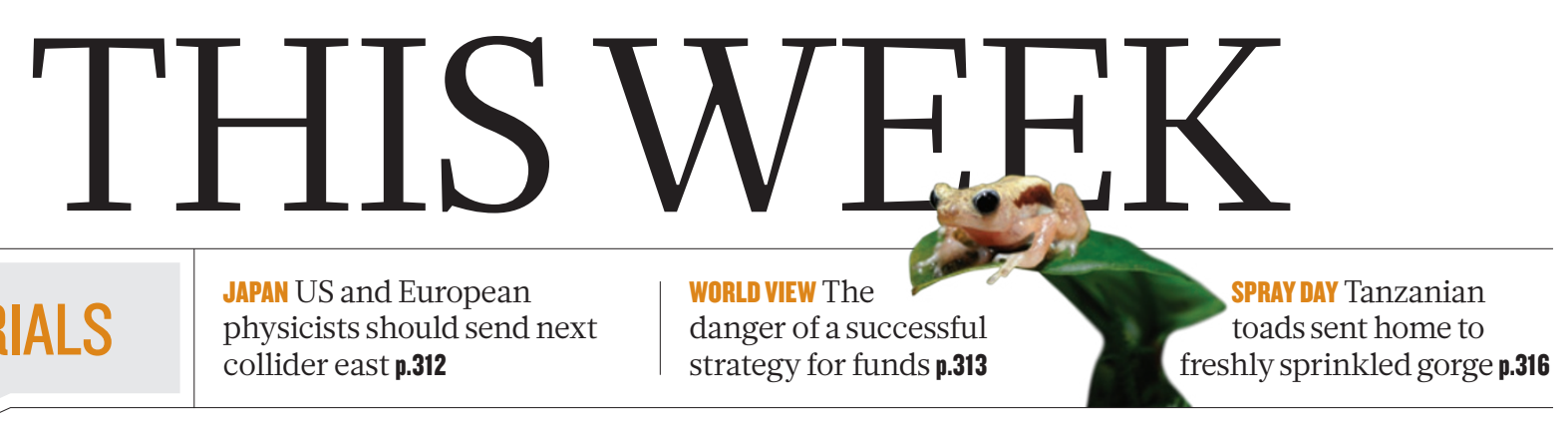

EDITORIALS physicists should send next collider east $\mathbf{p} . \mathbf{3 1 2}$

ORLD VIEW The strategy for funds p.313

\title{
The limits of free speech
}

\author{
Unregulated drug marketing stifles science and harms patients. To suggest otherwise is \\ an affront to liberty - not a protection of it.
}

$\mathrm{O}$ n 12 December, American drug giant Pfizer agreed to pay the US government more than US $\$ 55$ million in fines. Wyeth, a pharmaceutical company now owned by Pfizer, had overstated the benefits of its proton-pump inhibitor Protonix (pantoprazole), despite repeated warnings from the US Food and Drug Administration (FDA).

A government prosecutor said that the exaggerations were intentional and planned: "Wyeth tried to cheat the system by obtaining a limited FDA approval for Protonix, fully intending to promote this drug for additional, unapproved uses."

Collectively, drug companies have paid billions of dollars for similar offences. Again and again, the lure of increased sales overcomes the threat of potential penalties.

Another court ruling this month could tip the balance further, and not in the FDA's favour. This case, United States v. Caronia, relates to the conviction of a pharmaceutical salesman for Orphan Medical (taken over in 2005 by Jazz Pharmaceuticals based in Dublin), who was recorded telling a potential client that the drug Xyrem ( $\gamma$-hydroxybutyrate) could treat a variety of ills, including muscle disorders, chronic pain, Parkinson's disease and fibromyalgia. In fact, the drug had been approved by the FDA only for treating acute muscle weakness or excessive daytime sleepiness associated with narcolepsy. Xyrem can be abused and carries the FDA's strongest safety warning against use in children. In 2007, Jazz Pharmaceuticals agreed to a settlement of $\$ 20$ million in fines and compensation payments for the off-label marketing of Xyrem by Orphan.

However, a three-judge federal appeals court has now overturned the salesman's misdemeanour conviction, arguing two to one that off-label promotion should be protected as free speech. If the case continues all the way to the Supreme Court, and it probably will, it could have a profound effect on how drugs are marketed in the United States. Even under the existing regulations, drug companies face regular accusations that they promote illnesses that don't exist, craft clinical trials so as to show their drugs in the best light rather than to answer questions of efficacy and safety, and bury evidence about dangerous side effects.

Some in the field predict that to protect off-label marketing as free speech would unleash a barrage of television ads and expose patients to unnecessary, even fatal, side effects. "It's a potential catastrophe for patients, and I don't use that term lightly," says Steven Nissen, head of the Cleveland Clinic in Ohio.

At first glance, the free-speech argument has merit. If a pharmaceutical company wants to market a drug, it must first convince the FDA that it is safe and effective for a specific use. Once a drug has FDA approval, however, doctors are generally free to prescribe it as they choose. Indeed, 'off-label' prescriptions for medical uses without FDA approval are common: some doctors do prescribe Xyrem for complaints other than narcolepsy. If drugs work as doctors expect, both patients and pharmaceutical companies win. Why, then, should the United States continue to prohibit sales representatives from informing physicians of other possible uses for their drugs?

Off-label uses are off-label precisely because the drugs have not been studied well enough to understand their benefits and risks in this context. Doctors can learn about off-label uses and their drawbacks from talking to colleagues, attending conferences and reading the medical literature. These sources of information are influenced to some extent by drug companies' marketing policies, but they are clearly less biased than direct promotion to doctors by company salespeople.

Moreover, prohibitions on off-label promotion encourage good science. At present, companies must invest in "It's a potential further clinical trials to convince the FDA to catastrophe for broaden a drug's use. If the FDA cannot regupatients." late how drugs are marketed, the incentive to conduct such trials will evaporate.

Sometimes the investment pays off. Johnson \& Johnson, based in New Brunswick, New Jersey, recently announced an FDA-approved label expansion for its anti-testosterone drug Zytiga (abiraterone) to patients with advanced prostate cancer who have not already received chemotherapy. This could significantly increase Zytiga's sales.

But trials can also show that broadening the label is not justified. London-based AstraZeneca conducted a two-year, 1,300-patient trial hoping to show that its anticholesterol drug Crestor was superior to a competitor's. But Crestor did not perform better than Pfizer's Lipitor in preventing plaque build-up in arteries. In another case, large clinical trials revealed that two anti-arrhythmia drugs thought to protect against heart attacks actually increased death rates.

A weaker FDA with less authority to restrict off-label marketing could leave drug companies with even fewer incentives to show that off-label therapies work. This would harm patients and discourage good science.

\section{A burden weighed}

\author{
Despite some shortcomings, a global study \\ of health metrics should be applauded.
}

$\mathrm{T}$ The best evidence-based health policies are made on the basis of thorough and regular updates of the global burden of disease. Aid agencies need to know how and where to target their funding and monitor impact. Knowledge of what sickens and kills people can help health-care providers and researchers to tailor their priorities to needs and to long-term trends in the health of populations. Yet in many poor areas of the world, basic systems such as death certification are lacking, and quality health-care data are scarce and scattered. 